\title{
Migration and social determinants of mental health: Results from the Canadian Health Measures Survey
}

\author{
Bukola Salami, RN, PhD, ${ }^{1}$ Maryna Yaskina, $\mathrm{PhD},{ }^{2}$ Kathleen Hegadoren, RN, $\mathrm{PhD},{ }^{3}$ Esperanza Diaz, MBBS, $\mathrm{PhD},{ }^{4}$ \\ Salima Meherali, RN, PhD, ${ }^{5}$ Anu Rammohan, MA, PhD, ${ }^{6}$ Yoav Ben-Shlomo, MBBS, $\mathrm{PhD}^{7}$
}

\begin{abstract}
OBJECTIVES: Studies worldwide point to increased risk of mental health problems among immigrants. However, the data on Canadian immigrants' mental health are ambiguous. To address this, we examined the relationship of both self-perceived mental health and reported diagnosis of mood disorders with age, gender, migration status, time since migration, and social determinants of health factors.
\end{abstract}

METHODS: We analyzed three cycles of the Canadian Health Measures Survey. Our outcome variables were self-perceived mental health and reported diagnosis of mood disorders. We used weighted logistic regression to model time since migration conditional on age, gender, income, community belonging, education, and employment status for 12160 participants aged 15-79 years.

RESULTS: Recent (within 5 years) migrants reported better self-perceived mental health (odds ratio 3.98, 95\% confidence interval [CI]: 2.06-7.70) but this effect disappeared with longer time since immigration. Other predictors were older age, higher income, better sense of community belonging, and being employed. Similarly, diagnosis of mood disorders was less likely to be reported in recent migrants (odds ratio $0.23,95 \% \mathrm{Cl}$ : $0.10-0.53$ ) with some weak evidence that this was also seen among longer-term migrant residents ( $>10$ years). Diagnosis was also associated with older age, being a woman, lower income, weak sense of community belonging, and being unemployed.

DISCUSSION: Our findings indicate that migrants to Canada do not have worse mental health in general, though health and social policies need to attend to the socio-economic determinants, such as low income, unemployment, and a poor sense of community belonging, which contribute to population health outcomes.

KEY WORDS: Canada; immigrants; immigration; mental health; social determinants of health

A large number of immigrants arrive in Canada each year. In 2011, over 6.8 million individuals in Canada were born outside of the country. ${ }^{1}$ In 2014, Canada welcomed 260404 permanent residents. $^{2}$ This large influx of populations has a significant impact on health burden and care in Canada. Cumulative evidence suggests that immigrants, referred to as migrants* hereafter, arrive in Canada healthier than Canadianborn residents, a phenomenon termed the "healthy migrant effect". ${ }^{3}$ This extends beyond physical health indicators to encompass the mental health of immigrants in destination countries. ${ }^{4}$ However, evidence suggests that migrants' health deteriorates after some time in host societies. ${ }^{5}$

Diverse social determinants of health are implicated in migrant mental health disparities in Canada. Income, ${ }^{6}$ gender, ${ }^{7-10}$ employment status, ${ }^{11}$ social support network, and a sense of community belonging ${ }^{12,13}$ have all been shown to contribute to mental health status. Although there is evidence of an effect of age at migration on health, ${ }^{14}$ there is a paucity of knowledge about mental health outcomes of migrant populations in Canada across the lifespan and across gender.

\footnotetext{
* By immigrant or migrants, we mean individuals who are permanent residents or citizens of Canada but who were not born in Canada. This includes economic migrants, family class migrants, and refugees who are current permanent residents.
}

Studies worldwide point to increased risk of mental health problems and illnesses in migrant groups. ${ }^{4,15}$ A meta-analysis of

\footnotetext{
Author Affiliations

1. Assistant Professor, Faculty of Nursing, University of Alberta, Edmonton, $A B$

2. Biostatistician, Women and Children's Health Research Institute, University of Alberta, Edmonton, AB

3. Professor, Faculty of Nursing, University of Alberta, Edmonton, $A B$

4. Associate Professor, Department of Global Public Health and Primary Care, University of Bergen, Bergen, Norway

5. Postdoctoral Fellow, Faculty of Nursing, University of Alberta, Edmonton, $A B$

6. Professor, Department of Economics, University of Western Australia, Perth, Australia

7. Professor of Clinical Epidemiology, School of Social and Community Medicine, University of Bristol, Bristol, United Kingdom

Correspondence: Bukola Salami, PhD, Assistant Professor, Faculty of Nursing University of Alberta, Level 3, Edmonton Clinic Health Academy, 1140587 Avenue, Edmonton, AB T6G 1C9, Tel: 780-248-1801, E-mail: Bukola.salami@ualberta.ca

Acknowledgements: Funding for this project was provided by PolicyWise for Children and Families. This research has been facilitated by the Women and Children's Health Research Institute through the generous support of the Stollery Children's Hospital Foundation. It was stimulated by funding from a World University Network RDF grant and is part of the Health Outcomes of Migration Events (HOME) programme of research (http://www.wun.ac.uk/wun/research/view/home-healthoutcomes-of-migration-events). Through access to the Statistics Canada Data Centre, the research was supported by funds to the Canadian Research Data Centre Network from the Social Sciences and Humanities Research Council, the Canadian Institutes of Health Research, the Canadian Foundation for Innovation, and Statistics Canada. Although the research and analysis are based on data from Statistics Canada, the opinions expressed do not represent the views of Statistics Canada or the Canadian Research Data Centre Network.
}

Conflict of Interest: None to declare. 
21 studies from across the globe found that migrants experience higher rates of mental health problems than non-migrants. ${ }^{15}$ However, data on the mental health of migrant populations in Canada are equivocal. Findings from the Canadian Community Health Survey (CCHS) point to lower rates of psychiatric disorders, including unipolar and bipolar disorders, among first-generation migrants compared with Canadian-born residents. ${ }^{16-19}$ However, results from regional studies do not always concur with those from the CCHS. ${ }^{20,21}$ For example, some studies in specific Canadian cities report greater incidence rates of mental health disorders among migrant populations. ${ }^{20,22}$ The contradictory and equivocal findings of studies concerned with migrants' mental health make it relevant to analyze a broader range of available national data.

The purpose of this study is to quantify the burden of perceived mental health problems among migrant and non-migrant populations in Canada and to identify social factors associated with mental health. In this study, we analyzed data from the Canadian Health Measures Survey (CHMS) and examined the relationship of both self-perceived mental health and self-reported diagnosis of mood disorders with migration status, time since migration conditional on age, gender, and social determinants of health factors (income, community belonging, education, and employment status).

\section{METHODS}

We analyzed data from the CHMS, a national cross-sectional survey that includes personal interviews and physical measurements of a clustered random sample of Canadian residents. The CHMS is approved by the Health Canada Research Ethics Board. The survey has collected three cycles of data. Data collection for cycle 1 occurred from 2007 to 2009; cycle 2 from 2009 to 2011; and cycle 3 from 2012 to 2013. In each cycle a one-time cross-sectional survey was conducted. All three cycles were included in our analyses for a total sample size of approximately 17800 individuals. Of these, approximately 3400 people were born outside of Canada and around 14400 were Canadian born.

The CHMS includes individuals 3 to 79 years of age living in Canada's 10 provinces. Complete data on risk factors and outcomes of interest in our study were available for individuals $\geq 15$ years of age. The CHMS uses multi-stage sampling. There are two sampling frames based on data collection sites and household. The probability of selection for the survey is determined by multiplying the probability of selection at each stage. This is adjusted for non-response. To tackle non-response bias, the weight of non-respondent households was redistributed to respondents within homogeneous response groups. This redistribution is determined by Canada Census characteristics that are available for both non-participants and participants.

\section{Outcomes}

We used two outcome measures: a) self-perceived mental health and b) self-reported diagnosis of mood disorder. To assess selfperceived mental health status individuals were asked, "In general, would you say your mental health is excellent, very good, good, fair, or poor?" In our analysis, we have grouped individuals with "excellent", "very good", or "good" health and compared them with those with "fair" or "poor" health (binary variable). To ascertain a history of mood disorders, participants were asked, "Do you have a mood disorder such as depression, bipolar disorder, mania, or dysthymia?" We compared those reporting a mood disorder with those without a mood disorder.

\section{Covariates}

Age was categorized into five categories: 15-19, 20-34, 35-44, 45-64, and 65-80 years. Employment was assessed by asking whether the person had worked at a job or business in the previous 12 months, which yielded three categories: "Yes", "No" and "Not available for people 65 years old and older". Sense of community belonging was assessed by the question, "How would you describe your sense of belonging to your local community?" Sense of community belonging had four possible categories: "very strong", "somewhat strong", "somewhat weak" and "very weak". Immigration status was assessed by the country of birth: Canada or other. Time since immigration was categorized, a priori, as Canadian, 0-5 years, 6-10 years, and more than 10 years. Education was assessed by the highest level of education of the household. It had three categories: "less than secondary school graduation", "secondary school graduation or some postsecondary" and "post-secondary graduation".

\section{Statistical methods}

Weighted logistic regression was used to estimate the odds ratios and 95\% confidence intervals for migration status, time since immigration, age group, gender, income, sense of community belonging, education, and employment on self-perceived mental health and self-reported diagnosis of mood disorders. On the basis of the Box and Tidwell procedure, ${ }^{23}$ income was found to be linearly related to the logit of both dependent variables, so it was used as a continuous variable but rescaled so that the odds ratios reflected a change per $\$ 10,000$ increase in income. Because of the collinearity between immigration status and time since migration, we used the latter variable, as it is more informative in our models, but report the former for completeness. Bootstrap weights provided by Statistics Canada were included in the analysis to accommodate the survey design and non-response bias, and to ensure that the findings were representative of the Canadian population. All analyses were conducted using SAS 9.4 (SAS Institute Inc., Cary, NC).

\section{RESULTS}

In total, we analyzed data from 12160 participants. Of these, 9310 (76.6\%) were Canadians and 2850 (23.4\%) were migrants (see Table 1). Migrants were older and had lower income but a higher level of education, and they reported a sense of community belonging similar to that of the Canadian group.

\section{Self-perceived mental health}

Overall, there was no statistically significant difference in the mental health of immigrants versus non-immigrants in Canada (odds ratio [OR] 1.07, 95\% confidence interval [CI]: 0.87-1.31) adjusting for age group, gender, income, sense of belonging, education and employment. When we used time since migration, a more complex picture emerged. Recent migrants were almost four times more likely to report better mental health (OR 3.98, 95\% CI: 2.06-7.70), but this effect had fully attenuated with longer duration of residence. Other predictors of better mental health 
Table 1. Canadian Health Measures Survey (cycles 1, 2 and 3): Basic descriptive for sample stratified by immigrant status

\begin{tabular}{|c|c|c|c|}
\hline Variable & Total & Canadians & Immigrants \\
\hline & $N=12160$ & $\mathbf{N}=9310$ & $N=\mathbf{2 8 5 0}$ \\
\hline $\begin{array}{l}\text { Age, mean }(\mathrm{SE}) \\
15-19 \text { years }(\%) \\
20-34 \text { years }(\%) \\
35-44 \text { years }(\%) \\
45-64 \text { years }(\%) \\
65-80 \text { years }(\%)\end{array}$ & $\begin{array}{c}43.6(0.10) \\
7.84 \% \\
25.64 \% \\
17.64 \% \\
36.39 \% \\
12.50 \%\end{array}$ & $\begin{array}{c}42.8(0.19) \\
9.28 \% \\
26.50 \% \\
16.19 \% \\
36.21 \% \\
11.82 \%\end{array}$ & $\begin{array}{c}45.7(0.49) \\
3.87 \% \\
23.26 \% \\
21.62 \% \\
36.88 \% \\
14.37 \%\end{array}$ \\
\hline Men (\%) & $49.50 \%$ & $49.42 \%$ & $49.72 \%$ \\
\hline Income, mean $\$(S E)$ & $\$ 79,841(\$ 2,030)$ & $\$ 82,763(\$ 2,150)$ & $\$ 71,890(\$ 2,990)$ \\
\hline $\begin{array}{l}\text { Sense of community belonging } \\
\text { Very strong }(\%) \\
\text { Somewhat strong (\%) } \\
\text { Somewhat weak (\%) } \\
\text { Very weak }(\%)\end{array}$ & $\begin{array}{c}18.83 \% \\
44.24 \% \\
27.43 \% \\
9.49 \%\end{array}$ & $\begin{array}{c}18.46 \% \\
44.10 \% \\
27.87 \% \\
9.56 \%\end{array}$ & $\begin{array}{c}19.86 \% \\
44.62 \% \\
26.21 \% \\
9.31 \%\end{array}$ \\
\hline $\begin{array}{l}\text { Education } \\
\text { Less than secondary school graduation (\%) } \\
\text { Secondary school or some post-secondary (\%) } \\
\text { Post-secondary school graduation (\%) }\end{array}$ & $\begin{array}{c}5.91 \% \\
17.09 \% \\
77.00 \%\end{array}$ & $\begin{array}{c}6.31 \% \\
18.51 \% \\
75.18 \%\end{array}$ & $\begin{array}{c}4.80 \% \\
13.13 \% \\
82.08 \%\end{array}$ \\
\hline
\end{tabular}

Note: SE = standard error; this is used instead of the SD since the SD is very large because of the very large adjusted sample size and adjusted frequencies. Only percentages are given for categorical variables since adjusted frequencies are very large. It is possible to multiply these percentages and sample sizes to obtain the adjusted frequencies for the sample.

\begin{tabular}{|c|c|c|c|}
\hline Variable & Odds ratio* & $\mathbf{9 5} \%$ Confidence interval for odds ratio & p value \\
\hline $\begin{array}{l}\text { Age (years) } \\
15-19 \text { vs. } 65-80 \\
20-34 \text { vs. } 65-80 \\
35-44 \text { vs. } 65-80 \\
45-64 \text { vs. } 65-80\end{array}$ & $\begin{array}{l}0.45 \\
0.46 \\
0.42 \\
0.40\end{array}$ & $\begin{array}{l}0.25-0.80 \\
0.28-0.73 \\
0.27-0.65 \\
0.29-0.56\end{array}$ & $<0.0001$ \\
\hline $\begin{array}{l}\text { Gender } \\
\quad \text { Male vs. female }\end{array}$ & 0.91 & $0.67-1.22$ & 0.52 \\
\hline Income (rescaled per $\$ 10000$ ) & 1.16 & $1.11-1.22$ & $<0.0001$ \\
\hline $\begin{array}{l}\text { Sense of community belonging } \\
\text { Very strong vs. very weak } \\
\text { Somewhat strong vs. very weak } \\
\text { Somewhat weak vs. very weak }\end{array}$ & $\begin{array}{l}3.91 \\
4.89 \\
2.42\end{array}$ & $\begin{array}{l}2.42-6.32 \\
3.20-7.48 \\
1.60-3.67\end{array}$ & $<0.0001$ \\
\hline $\begin{array}{l}\text { Education } \\
\text { Less than secondary school graduation vs. post-secondary graduation } \\
\text { Secondary school graduation vs. post-secondary graduation }\end{array}$ & $\begin{array}{l}0.76 \\
0.67\end{array}$ & $\begin{array}{l}0.50-1.15 \\
0.46-0.97\end{array}$ & 0.06 \\
\hline $\begin{array}{l}\text { Employment } \\
\text { Unemployed vs. employed }\end{array}$ & 0.51 & $0.34-0.75$ & 0.0006 \\
\hline $\begin{array}{l}\text { Time since immigration } \\
\text { Canadians vs. migrants } 0-5 \text { years } \\
\text { Canadians vs. } 6-10 \text { years } \\
\text { Canadians vs. }>10 \text { years }\end{array}$ & $\begin{array}{l}3.98 \\
0.66 \\
1.01\end{array}$ & $\begin{array}{l}2.06-7.70 \\
0.25-1.78 \\
0.58-1.74\end{array}$ & 0.0006 \\
\hline
\end{tabular}

were older age, higher income, better sense of community belonging, and being employed (see Table 2). There was little evidence that gender or education was predictive, but there was a suggestive trend $(p=0.06)$ that higher education was associated with better mental health, and individuals with secondary school graduation were less likely to report excellent, very good, or good self-perceived mental health than people with post-secondary graduation (OR 0.67, 95\% CI: 0.46-0.97).

\section{Self-reported diagnosis of mood disorders}

Migrants were less likely to report a diagnosis of mood disorders (OR 0.80, 95\% CI: 0.69-0.94, $p=0.005$ ). When we examined this by duration of residence in Canada, the pattern was non-linear, so that the lowest risk was seen in the immediate five years followed by little difference between 6 and 10 years and then a less reduced risk after 10 years of residence. A higher probability of diagnosis was associated with middle age (inverted U-shape with age), female gender, lower income, weak sense of community belonging, and unemployment (see Table 3). Education was not a predictor in the model conditional on the other covariates.

\section{DISCUSSION}

The secondary data analyses of the CHMS indicated that migration status per se was not associated with self-reported well-being but 


\begin{tabular}{|c|c|c|c|}
\hline Variable & Odds ratio* & $\mathbf{9 5 \%}$ Confidence interval for odds ratio & $p$ value \\
\hline $\begin{array}{l}\text { Age (years) } \\
15-19 \text { vs. } 65-80 \\
20-34 \text { vs. } 65-80 \\
35-44 \text { vs. } 65-80 \\
45-64 \text { vs. } 65-80\end{array}$ & $\begin{array}{l}1.08 \\
1.68 \\
2.47 \\
2.31\end{array}$ & $\begin{array}{l}0.72-1.63 \\
1.02-2.78 \\
1.80-3.39 \\
1.74-3.07\end{array}$ & $<0.0001$ \\
\hline $\begin{array}{l}\text { Gender } \\
\text { Male vs. female }\end{array}$ & 0.58 & $0.46-0.73$ & $<0.0001$ \\
\hline Income (rescaled by $1 / 10000$ ) & 0.94 & $0.91-0.97$ & 0.0002 \\
\hline $\begin{array}{l}\text { Sense of community belonging } \\
\text { Very strong vs. very weak } \\
\text { Somewhat strong vs. very weak } \\
\text { Somewhat weak vs. very weak }\end{array}$ & $\begin{array}{l}0.36 \\
0.44 \\
0.54\end{array}$ & $\begin{array}{l}0.24-0.53 \\
0.31-0.61 \\
0.38-0.75\end{array}$ & $<0.0001$ \\
\hline $\begin{array}{l}\text { Employment } \\
\text { Unemployed vs. employed } \\
\text { Employed vs. senior non-employed }\end{array}$ & $\begin{array}{l}1.85 \\
0.29\end{array}$ & $\begin{array}{l}1.39-2.48 \\
0.16-0.52\end{array}$ & $<0.0001$ \\
\hline $\begin{array}{l}\text { Time since immigration } \\
\text { Canadians vs. migrants } 0-5 \text { years } \\
\text { Canadians vs. } 6-10 \text { years } \\
\text { Canadians vs. }>10 \text { years }\end{array}$ & $\begin{array}{l}0.23 \\
1.05 \\
0.66\end{array}$ & $\begin{array}{l}0.10-0.53 \\
0.37-3.01 \\
0.46-0.94\end{array}$ & 0.001 \\
\hline $\begin{array}{l}\text { Education } \\
\text { Less than secondary school graduation vs. post-secondary graduation } \\
\text { Secondary school graduation vs. post-secondary graduation }\end{array}$ & $\begin{array}{l}1.33 \\
0.97\end{array}$ & $\begin{array}{l}0.94-1.90 \\
0.71-1.30\end{array}$ & 0.19 \\
\hline
\end{tabular}

was associated with a reduced odds of being diagnosed with a mood disorder as compared with Canadians, conditional on other socio-demographic factors. This observation is consistent with data from the CCHS, which shows lower risk of mental illness among migrants. ${ }^{16-19}$ However, it is inconsistent with international data on migrants' mental health, which shows higher risk among migrants, though these results may not be generalizable to Canada per se. ${ }^{4,15}$

Our analyses revealed that participants who had recently migrated to Canada, within 5 years, had better mental health scores than those who had migrated to Canada more than 10 years before. Prior studies have shown that within about 10 years of living in Canada, migrant health deteriorates and converges to Canadian-born levels of mental health. ${ }^{24-26}$ Indeed, using the CCHS database, Ali reported that the healthy migrant mental health effect was lost over time, and the mental health of long-term migrants (10+ years in Canada) did not significantly differ from the non-migrant population. ${ }^{16}$ This pattern of better mental health in recent migrants was consistent with our observation of a $67 \%$ relative reduction in the odds ratio for self-reported diagnosis. We cannot differentiate whether this duration effect is secondary to migrant acculturation with the host's environment or reflects a cohort effect, in which more recent migrant groups are selected for better mental health than past cohorts. In addition to acculturation with host environment and cohort effect, other possible explanations include regression to the mean, better access and use of mental health services (thus resulting in more diagnosis of mental illness) and increased medicalization of immigrants' lived experiences, as in the case of mainstream Canadians.

Overall, our analyses demonstrated that socio-demographic factors were also associated with both self-perceived mental health and self-reported diagnosis of mood disorders. Individuals aged 65-80 years reported better mental health than younger individuals. The Mental Health Commission of Canada has also proposed that age has an effect on the diagnosis of mental illness within the general Canadian population. ${ }^{27}$ The estimated 12-month prevalence rate of mental illness among Canadians aged $13-29$ is $30 \%$, whereas the prevalence rate among individuals aged 60-69 is far lower, at 10\%.

Economic hardship is also a significant determinant of health and linked to health disparities. One of the most significant factors contributing to mental health in our analysis is unemployment and lower household income. Migrants face many barriers in accessing employment in Canada, such as the lack of acceptance of their foreign credentials by professional bodies and employers, language-related barriers, and lack of prior Canadian work experience. $^{25,28}$ The inability to secure suitable work compels many migrants to take up low-skilled, precarious work to survive. We noted a difference in trends between educational level (higher in migrants) and income (lower in migrants), suggesting inequitable access to higher paid jobs (see Table 1). A number of studies have identified the importance of financial resources to the psychological and physical well-being of migrant groups. ${ }^{24,28}$ Thus, programs and services that contribute to improving employment outcomes and thus income status for migrants may serve to improve their mental health and ultimately population health in Canada.

A sense of community belonging was strongly, directly associated with self-perceived mental health and self-reported diagnosis of mood disorders. The odds of having excellent, very good, or good self-perceived mental health were around four times higher for those who had a strong sense of community belonging than for people with a very weak sense of community belonging. This may reflect a protective effect of social cohesiveness, but one must also consider the possibility of "reverse causation", so that participants with low mood report their experience of community belonging in more negative terms. Previous research studies have similarly found that individuals with low social support and 
community belonging have higher odds of reporting mental disorders, and the association was strongest among recent migrants. ${ }^{12,13}$ The relationship between social support and mental health may be explained by the fact that strong social support and community belonging provide people with positive experiences, and a lack of positive social relationships and low social support appeared to have more pronounced adverse effects on the mental health of migrant populations. ${ }^{12,29}$ Migrants experience multiple stressors during the settlement process. A strong social support network may help them improve their ability to overcome settlement challenges. ${ }^{12,13}$

Gender showed discordant results with our outcomes. While we found no relationship between gender and self-perceived mental health, our analysis demonstrated that women are more likely than men to report a diagnosis of mood disorder. Several studies report that women (including migrant women) experience more nonpsychotic mental health disorders (e.g., depression) and are more likely to use mental health services than men., ${ }^{6,8,10,29}$ Migrant women's mental health can be influenced by a range of factors. For instance, in most societies women are assigned subordinate positions to men and experience systematic discrimination in access to power and resources, and this may be worse for migrant women.

These analyses have a number of important limitations. A major drawback of this study is our limited sample size. This resulted in us not being able to undertake an intragroup analysis of migrants in Canada, and we recognize the weakness of combining what are heterogeneous groups into one category. In addition, we did not have the power to test for important interactions, such as time since migration and gender. Future studies could further examine differences in mental health status across diverse migrant and other subgroups. Second, the question about diagnosis of mood disorders may be problematic. Within this question: "Do you have a mood disorder such as depression, bipolar disorder, mania, or dysthymia", immigrants and non-immigrants may not fully understand what dysthymia, bipolar, or mania means. Further research should utilize clinical assessment of mental illness rather than self-report of a diagnosis of mood disorders. Third, the reported associations are cross-sectional rather than longitudinal. This limits the ability to determine causality, as in our finding about community belonging. Our analyses suggest a waning effect of positive mental health among recent migrants. However, acculturation and cohort effect are plausible explanations. Thus, this finding needs to be confirmed in longitudinal studies with repeat outcome measures. There is also a need for further qualitative research evidence to provide a deeper understanding of the roles of community belonging and income on migrant mental health. This will help to develop social, immigration, and health policies that can contribute to migrants' mental health.

Comparative studies across major destination countries on the influence of policies and diverse determinants of health may help shed light on viable immigration and health policy approaches to address the mental health of migrants. Given evidence that migrants' mental health diminishes after a period of time in Canada, an upstream approach is needed to tackle the diverse influences of multiple determinants of health throughout the migration and settlement process. Moreover, our results indicate that mental health service provision for migrants should not just be limited to the initial years in Canada, as the experience of longer-term migrants may be more problematic and require mental health interventions to maintain and improve their mental health.

\section{REFERENCES}

1. Statistics Canada. Immigration and Ethnocultural Diversity in Canada. Ottawa, ON: Statistics Canada, 2013. Available at: http://www12.statcan.gc.ca/nhsenm/2011/as-sa/99-010-x/99-010-x2011001-eng.pdf (Accessed July 15, 2016).

2. Citizenship and Immigration Canada. Canada Facts and Figures: Immigrant Overview - Permanent Residents, 2014. Ottawa, ON: Citizenship and Immigration Canada, 2015.

3. Kennedy S, Kidd MP, McDonald JT, Biddle N. The healthy immigrant effect: Patterns and evidence from four countries. J Int Migr Integr 2015;16(2):317-32 doi: 10.1007/s12134-014-0340-x.

4. Abebe DS, Lien L, Hjelde KH. What we know and don't know about mental health problems among immigrants in Norway. J Immigr Minor Health 2014; 16(1):60-67. PMID: 23117694. doi: 10.1007/s10903-012-9745-9.

5. De Maio FG, Kemp E. The deterioration of health status among immigrants to Canada. Glob Public Health 2010;5(5):462-78. PMID: 19513909. doi: 10.1080/ 17441690902942480.

6. Clarke DE, Colantonio A, Rhodes AE, Escobar M. Pathways to suicidality across ethnic groups in Canadian adults: The possible role of social stress Psychol Med 2008;38:419-31. PMID: 17976253. doi: 10.1017/S003329170700 2103.

7. Hollander A, Bruce D, Burström B, Ekblad S. Gender-related mental health differences between refugees and non-refugee immigrants: A cross-sectional register-based study. BMC Public Health 2011;11(180):1-8. PMID: 21435212. doi: 10.1186/1471-2458-11-180.

8. Kwak K, Rudmin F. Adolescent health and adaptation in Canada: Examination of gender and age aspects of the healthy immigrant effect. Int J Equity Health 2014;13(1):103. PMID: 25394371. doi: 10.1186/s12939-0140103-5.

9. Pahwa P, Karunanayake P, McCrosky J, Thorpe L. Longitudinal trends in mental health among ethnic groups in Canada. Chronic Dis Inj Can 2012; 32(3):164-76. PMID: 22762903.

10. Piccinelli M, Wilkinson G. Gender differences in depression. Br J Psychiatry 2000;177(6):486-92. doi: 10.1192/bip.177.6.486.

11. Rodriguez E, Frongillo EA, Chandra P. Do social programmes contribute to mental well-being? The long-term impact of unemployment on depression in the United States. Int J Epidemiol 2001;30:163-70. PMID: 11171879. doi: 10. 1093/ije/30.1.163.

12. Chadwick KA, Collins PA. Examining the relationship between social support availability, urban center size, and self-perceived mental health of recent immigrants to Canada: A mixed-methods analysis. Soc Sci Med 2015;128: 220-30. PMID: 25621402. doi: 10.1016/j.socscimed.2015.01.036.

13. Puyat JH. Is the influence of social support on mental health the same for immigrants and non-immigrants? J Immigr Minor Health 2013;15(3):598-605 PMID: 22711218, doi: 10.1007/s10903-012-9658-7.

14. Gee EM, Kobayashi KM, Prus SG. Examining the healthy immigrant effect in mid- to later life: Findings from the Canadian Community Health Survey. Can J Aging 2004;23(Suppl 1):S61-69. PMID: 15660311.

15. Bourque FI, van der Ven E, Malla A. A meta-analysis of the risk for psychotic disorders among first- and second-generation immigrants. Psychol Med 2011; 41(5):897-910. PMID: 20663257. doi: 10.1017/S0033291710001406.

16. Ali J. Mental health of Canada's immigrants. Health Rep 2002;13:101-7.

17. Menezes NM, Georgiades $\mathrm{K}$, Boyle $\mathrm{MH}$. The influence of immigrant status and concentration on psychiatric disorder in Canada: A multi-level analysis Psychol Med 2011;41(10):2221-31. PMID: 21349240. doi: 10.1017/S0033 291711000213

18. Schaffer A, Cairney J, Cheung A, Veldhuizen S, Kurdyak P, Levitt A. Differences in prevalence and treatment of bipolar disorder among immigrants: results from an epidemiologic survey. Can I Psychiatry 2009; 54(11):734-42. PMID: 19961661. doi: 10.1177/070674370905401103.

19. Stafford M, Newbold BK, Ross NA. Psychological distress among immigrants and visible minorities in Canada: A contextual analysis. Int J Soc Psychiatry 2011;57(4):428-41. PMID: 20378661. doi: 10.1177/0020764010365407.

20. Kisely S, Terashima M, Langille D. A population-based analysis of the health experience of African Nova Scotians. Can Med Assoc J 2008;179:653-58. PMID: 18809896. doi: 10.1503/cmaj.071279.

21. Tousignant M, Habimana E, Biron C, Malo C, Sidoli-Leblanc E, Bendris N. The Quebec adolescent refugee project: Psychopathology and family variables in a sample from 35 nations. I Am Acad Child Adolesc Pschyciatry 1999 38(11):1426-32. PMID: 10560230. doi: 10.1097/00004583-199911000-00018

22. Mechakra-Tahiri S, Zunzunequi MV, Seguin L. Self-rated health and postnatal depressive symptoms among immigrant mothers in Quebec. Women Health 2007;45(4):1-17. PMID: 18032165. doi: 10.1300/J013v45n04_01.

23. Box GEP, Tidwell PW. Transformation of the independent variables. Technometrics 1962;4:531-50. doi: 10.1080/00401706.1962.10490038. 
24. Islam F. Examining the "healthy immigrant effect" for mental health in Canada. Univ Toronto Med J 2013;90(4):169-75.

25. Ng E, Omariba WR. Is there a healthy immigrant effect in mental health? Evidences from population-based health surveys in Canada. In: Canadian Issues Summer 2010: Immigrant Mental Health. Montreal, QC: Association for Canadian Studies, 2010; 23-28.

26. Vang Z, Sigouin J, Flenon A, Gagnon A. The healthy immigrant effect in Canada: A systematic review. Population Change and Life Course Strategic Knowledge Cluster Discussion Paper Series 2015;3(1). Available at: http://ir.lib. uwo.ca/pclc/vol3/iss1/4 (Accessed October 10, 2016).

27. Mental Health Commission of Canada. Making the Case for Investing in Mental Health in Canada. Ottawa, ON: Mental Health Commission of Canada, 2013. Available at: http://www.mentalhealthcommission.ca/English/system/files/ private/document/Investing_in_Mental_Health_FINAL_Version_ENG.pdf (Accessed July 11, 2016).

28. Robert AM, Gilkinson T. Mental Health and Well-Being of Recent Immigrants in Canada: Evidence from the Longitudinal Survey of Immigrants to Canada (LSIC). Ottawa, ON: Research and Evaluation Branch, Citizenship and Immigration Canada, 2012. Available at: http://www.cic.gc.ca/english/resources/research/ mental-health.asp (Accessed October 12, 2016).

29. Delara M. Social determinants of immigrant women's mental health. Adv Public Health 2016;2016:1-11. doi: 10.1155/2016/9730162.

Received: February 2, 2017

Accepted: April 29, 2017

\section{RÉSUMÉ}

OBJECTIFS : Des études du monde entier font état d'un risque accru de troubles de santé mentale chez les immigrants. Les données sur la santé mentale des immigrants canadiens sont toutefois ambiguës. Pour y remédier, nous avons examiné les relations entre la santé mentale autoperçue et les déclarations de diagnostics de troubles de l'humeur, d'une part, et l'âge, le sexe, le statut migratoire, le temps écoulé depuis la migration et les déterminants sociaux de la santé d'autre part.
MÉTHODE : Nous avons analysé trois cycles de l'Enquête canadienne sur les mesures de la santé. Nos variables de résultats étaient la santé mentale autoperçue et les déclarations de diagnostics de troubles de l'humeur. Nous avons eu recours à la régression logistique pondérée pour modéliser le temps écoulé depuis la migration en tenant compte de l'âge, du sexe, du revenu, du sentiment d'appartenance à la collectivité, de l'instruction et de la situation d'emploi de 12160 participants de 15 à 79 ans.

RÉSULTATS : Les migrants récents (depuis moins de 5 ans) ont fait état d'une meilleure santé mentale autoperçue (rapport de cotes 3,98, intervalle de confiance $[\mathrm{IC}]$ de $95 \%: 2,06-7,70)$, mais cet effet disparaissait avec le temps écoulé depuis l'immigration. Les autres variables prédictives étaient l'âge plus avancé, le revenu plus élevé, un meilleur sentiment d'appartenance à la collectivité et le fait d'avoir un emploi. De même, le diagnostic de troubles de l'humeur était moins susceptible d'être déclaré par les migrants récents (rapport de cotes 0,23 , IC de $95 \%: 0,10-0,53$ ); quelques données probantes fragiles ont par ailleurs indiqué que ce diagnostic était présent chez les migrants résidents arrivés depuis plus longtemps (>10 ans). Le diagnostic était aussi associé à l'âge plus avancé, au sexe féminin, au revenu plus faible, au moindre sentiment d'appartenance à la collectivité et au chômage.

DISCUSSION : Nos constatations montrent que les migrants au Canada n'ont pas une moins bonne santé mentale en général, mais que les politiques sociosanitaires doivent s'attarder aux déterminants socioéconomiques comme le faible revenu, le chômage et la fragilité du sentiment d'appartenance à la collectivité, qui contribuent aux résultats de santé des populations.

MOTS CLÉS : Canada; immigrants; immigration; santé mentale; déterminants sociaux de la santé 